\title{
AFETOS E IMPLICAÇÕES \\ PSICOSSOCIAIS DO VIVER SOB AMEAÇAS DE DESAPROPRIAÇÃO DO ESPAÇO
}

\author{
AFECTOS E IMPLICACIONES PSICOSOCIALES \\ DE VIVIR BAJO AMENAZAS DE EXPROPIACIÓN ESPACIAL \\ AFFECTIONS AND PSTCHOSOCIAL IMPLICATIONS \\ OF LIVING UNDER THREATS OF SPACE EXPROPRIATION
}

\author{
Fábio Pinheiro Pacheco' ${ }^{1}$ e Zulmira Áurea Cruz Bomfim ${ }^{1}$
}

${ }^{1}$ Universidade Federal do Ceará, Fortaleza/CE, Brasil

\begin{abstract}
RESUMO: Este artigo objetiva apresentar indicadores afetivos e as implicações psicossociais do contexto de ameaças de desapropriação do espaço vividas por moradoras de uma comunidade de Fortaleza, Ceará. Trata-se de uma pesquisa qualitativa, realizada com 17 moradoras/es, utilizando-se de entrevistas semiestruturadas para o levantamento das informações; e a análise de conteúdo para o tratamento dos dados. Com base na Psicologia Ambiental e na Psicologia Social, discute-se transformações no cotidiano; e afetos e implicações psicossociais. Como elementos despotencializadores, foram identificados conflito interno entre as/os moradoras/es, venda da comunidade (desapropriação), demolição das casas e sentimentos que entristecem; quanto aos potencializadores, destacaram-se integração entre as/os moradoras/ es, própria moradia (permanência), momentos de entretimento e sentimentos que alegram.
\end{abstract}

PALAVRAS-CHAVE: Afetividade; Desapropriação do espaço; Comunidade; Psicologia Social; Sofrimento ético-político.

RESUMEN: Este artículo tiene como objetivo presentar indicadores afectivos y las implicaciones psicosociales del contexto de amenazas de expropiación espacial que viven los habitantes de una comunidad en Fortaleza, Ceará. Se trata de una investigación cualitativa, realizada con 17 residentes, utilizando entrevistas semiestructuradas para recopilar información; y análisis de contenido para el procesamiento de datos. Con base en Psicología Ambiental y Psicología Social, se discuten los cambios en la vida diaria; y afectos e implicaciones psicosociales. Como elementos desempoderantes, se identificaron conflictos internos entre vecinos, venta de la comunidad (expropiación), demolición de viviendas y tristeza; en cuanto a los potenciadores, se destacaron la integración entre vecinos, la propia vivienda (permanencia), momentos de entretenimiento y sentimientos que alegran.

PALABRAS CLAVE: Afecto; Expropiación del espacio; Comunidad; Psicología Social; Sufrimiento ético-político.

ABSTRACT: This article aims to present affective indicators and the psychosocial implications of the context of threats of space expropriation experienced by residents of a community in Fortaleza, Ceará. This is a qualitative research, carried out with 17 residents, using semi-structured interviews to gather information; and content analysis for data processing. Based on Environmental Psychology and Social Psychology, changes in daily life are discussed; and affects and psychosocial implications. As disempowering elements, internal conflict between residents, sale of the community (expropriation), demolition of houses and sad feelings were identified; as for the enhancers, integration among residents, housing themselves (staying), moments of entertainment and feelings that rejoice were highlighted. KEYWORDS: Affection; Expropriation of space; Community; Social Psychology; Ethical-political suffering. 


\section{Introdução}

A Vila Vicentina da Estância, também conhecida como Vila Cinzenta, é uma comunidade urbana de Fortaleza cuja história remonta da primeira metade do século XX. Localizada no bairro Dionísio Torres, a comunidade surge em 1938, quando o terreno onde as casas foram construídas foi doado pelo farmacêutico Dionísio Torres para uma sociedade beneficente, com o intuito de ajudar viúvas pobres e/ou retirantes da seca a terem um lar (Duarte, Pacheco \& Rocha, 2017). Conforme o cordel "A História da Vila Cinzenta" de autoria de uma antiga moradora, as casas foram construídas em um recanto distante da cidade, desconhecido pelas pessoas, "Abrigando inúmeros velhinhos / Sem teto, sem comida e sem lar", a fim de que essas mulheres pudessem se fortalecer e continuar com suas vidas, superando as adversidades da pobreza (Albuquerque, 1970, p. 1) ${ }^{1}$.

Com o passar do tempo, as primeiras moradoras foram morrendo, no entanto as casas passaram para seus filhos, que foram construindo suas próprias famílias; e outras/os moradoras/es foram chegando à comunidade (Duarte et al., 2017). Estruturalmente, a Vila é formada por 44 casas de paredes conjugadas, com as frentes para as ruas e os fundos para um grande quintal comunitário; e 01 capela. No passado, a comunidade também tinha um consultório médico, uma escola e contava com a administração de generais e outros líderes religiosos para a manutenção dos espaços e organização das relações estabelecidas na comunidade (Albuquerque, 1970; Duarte et al., 2017).

Geograficamente, a Vila é delimitada pela Avenida Antônio Sales e pelas ruas Tibúrcio Cavalcante, Nunes Valente e Dom Expedito Lopes, pertencendo ao terceiro bairro de melhor Índice de Desenvolvimento Humano (0,860) de Fortaleza (Iplanfor, 2020). Pelo Plano Diretor de Fortaleza de 2009, essa área é identificada como uma Zona Especial de Interesse Social (ZEIS), a ZEIS Dionísio Torres, que consiste em uma ferramenta de combate às segregações socioespaciais, prevista em política pública nacional estabelecida pelo Estatuto da Cidade. Nessas zonas, os terrenos devem somente ser utilizados para a construção de moradias sociais, no entanto, esta ZEIS ainda não foi regulamentada (Iplanfor, 2020).

Com base na Psicologia Comunitária, pode-se compreender a Vila como uma comunidade dinâmica que reflete as instâncias da sociedade e o modo de vida de um povo, um "lugar de moradia, de permanência estável e duradoura, de orientação e de proteção da individualidade ante a natureza e a sociedade" (Góis, 2008, p. 85). Desse modo, a comunidade apresenta-se como um lugar de permanência estável e duradoura no qual as/os moradoras/es estabelecem uma relação entre si; também se configurando como um espaço de conflitos e contradições (Góis, 2005).

Há alguns anos, a Vila vem enfrentando ameaças de desapropriação. As/Os moradoras/es relatam que sofrem ameaças de remoção, assédio moral e pressão psicológica por parte da instituição religiosa beneficente para quem o farmacêutico Dionísio Torres doou o terreno. A instituição alega problemas financeiros, por isso pretende vender o terreno da comunidade para o setor imobiliário que se responsabilizaria de pagar indenizações às/aos moradoras/es, oferecendo uma quantia em dinheiro ou um apartamento na região metropolitana de Fortaleza. Durante o auge dos conflitos, em 2016, três foram demolidas e outras cinco foram destelhadas; e as/os moradoras/es que permanecem se dividem entre as/os que buscam resistir às ameaças e as/os que, temendo perder tudo, negociam a saída, acirrando ainda mais os conflitos e as contradições do lugar (Gondin \& Rocha, 2019). 
No âmbito jurídico, a desapropriação é uma medida pela qual o Poder Público, ou terceiros mediante acordo com a Lei, retira a posse do dono de determinada propriedade sob a justificativa de necessidade, utilidade pública ou interesse social. No âmbito da Psicologia Ambiental, desapropriação é um processo ou meio de fazer com que as/os moradoras/es não mais sintam que esses espaços lhes são pertencentes, agindo alheias/os a eles (Pol, 1996). Com efeito, se as pessoas não se apropriam dos espaços, não os transformam em lugares significativos, elas não se mobilizam em sua defesa.

Entende-se que a apropriação do espaço é um processo pelo qual as pessoas, ao transformar os espaços mediante suas ações, imprimem suas marcas e, ao mesmo tempo, incorporam-nos em seus processos cognitivos (organização, orientação etc.) e afetivos (apego ao lugar, autoestima etc.) (Cavalcante \& Elias, 2011; Pol, 1996). Nesse processo, as pessoas atribuem qualidades aos espaços e, pela interação dialética, constituem suas identidades, orientam-se simbólica e afetivamente e articulam suas ações, singulares e coletivas. No entanto, Pol (1996) aponta que a estrutura social atual busca, por meio das relações de poder, fazer com que poucos espaços sejam apropriados por parte de todas/os, diminuindo as implicações e mobilizações de defesas pelos lugares. Nesses casos, pode-se pensar que, muitas vezes, a desapropriação do espaço, tanto física como sócio psicologicamente, pode ser uma ação que contribui com a segregação socioespacial, tornando-se necessário compreender as relações pessoa-ambiente em contexto de desapropriação não apenas pela materialidade da ação, a desvinculação física, mas abrangendo as dimensões históricas, sociais, jurídico-políticas e socioafetivas (Pacheco, Martins, \& Bomfim, 2020).

Nesse sentido, acredita-se que a afetividade (Sawaia, 2009, 2011) pode ser uma categoria de análise tanto de aspectos relacionados às vinculações sujeito-comunidade como também de questões sociais e políticas que perpassam o contexto de segregação socioespacial concretizados por processos de remoção de comunidades. Sawaia (2011, p. 100) define afetividade "como a tonalidade e a cor emocional que impregna a existência do ser humano", podendo se manifestar pela integração das emoções e dos sentimentos. Como produções psicossociais, as emoções são reações afetivas momentâneas, normalmente com grande intensidade e alguma manifestação biológica (que também são socialmente codificadas); e os sentimentos, estados afetivos mais duradouros, podendo ser modificados com o tempo (Montero, 2004; Sawaia, 2011).

A partir dessa integração, além do caráter mediacional na constituição do psiquismo (Lane, 2006), a afetividade demarca uma capacidade de o indivíduo transformar seus instintos na consciência, dotando-lhes de significados, mediando as afecções a partir dos signos socialmente construídos, podendo aumentar e diminuir a sua potência de ação no encontro com os outros e as coisas (Espinosa, 2010; Sawaia, 2011). A afetividade, então, torna-se uma categoria de ação-mediadora e de transformação da consciência humana, podendo os afetos serem potencializadores, aumentando o poder de ação das pessoas, elevando a força de existir e perseverar no seu próprio ser; os afetos despotencializadoras, que atuam como força de padecimento, diminuindo a força do indivíduo, levando-o a passividade (Sawaia, 2009; Bomfim, 2010).Na relação dialética pessoa-ambiente, entende-se que todo ambiente provoca emoções e afeta o modo de agir das pessoas (Bomfim, Delabrida, \& Ferreira, 2018), sendo a compreensão dessa afetividade um indicador de ação de como habitante se implica na comunidade, na cidade e na sociedade, repercutindo em uma ética cidadã (Bomfim, 2010). 
Diante disso, este trabalho objetiva apresentar indicadores afetivos e as implicações psicossociais do contexto de ameaças de desapropriação do espaço vividas por moradoras/ es de uma comunidade de Fortaleza, Ceará. Volta-se para a compreensão de como as/os moradoras/es vêm vivenciando a comunidade a partir das ameaças de remoção, observando as alterações no cotidiano da comunidade, as dinâmicas das relações comunitárias e os afetos decorrentes das ameaças de desapropriação.

\section{Método}

Trata-se de um estudo qualitativo, com a aprovação do Comitê de Ética, realizado com 17 moradoras/es (14 mulheres e 03 homens, com idades entre 25 e 81 anos) da Vila Vicentina, Fortaleza-Ce. Na comunidade, há 15 famílias que resistem à desapropriação, desse modo, as/os participantes foram selecionadas/os de forma que cada família tivesse uma/um representante (em duas famílias diferentes, marido e esposa quiseram participar, por isso há 17 participantes). As/Os participantes atribuíram nomes fictícios a si mesmas/os para serem mencionadas/os no estudo. Para a construção do corpus, foram realizadas entrevistas semiestruturadas a fim de apreender do sentido que as/os moradoras/ es constroem sobre suas vivências, acontecimentos, modos de compreender e interpretar a situação, as crenças e referências normativas etc. (Gaskell, 2002), possibilitando o levantamento de informações sobre a história do lugar e sobre o modo de vida no contexto de ameaça de desapropriação do espaço.

Nesse sentido, tomou-se como base as seguintes perguntas: "1) Na Vila Vicentina, o que te alegra e o que te entristece?"; 2) "Como você se sente no atual momento da Vila Vicentina?”; e 3) "Como as ameaças de desapropriação afetaram o seu cotidiano?” A partir da Análise de Conteúdo (Bardin, 1977), foi possível identificar os afetos e as implicações psicossociais do contexto de desapropriação do espaço, compreender as vivências em relação ao ambiente e às relações comunitárias.

\section{Resultados e discussões}

Para desenvolver as discussões sobre as repercussões das ameaças de desapropriação, pautou-se nas percepções das/os moradoras/es em relação às vivências na comunidade, considerando aspectos físicos, sociais e, principalmente, afetivos. A análise voltou-se, então, para a apreensão dos fatores que poderiam potencializar as ações bem como mapear os indicadores despotencializadores. Para melhor apresentação dos resultados, foram organizadas duas seções principais, a saber, transformações no cotidiano; e afetos e implicações psicossociais.

\section{Transformações no cotidiano}

Quando uma intervenção urbana está por acontecer, alterando os lugares aos quais as pessoas estão vinculadas, torna-se indispensável o entendimento das diversas implicações que essas transformações podem ocasionar, uma vez que estas podem ou não serem integradas aos referentes simbólicos e sociais das pessoas (Pol, 1996). Quando a intervenção 
é integrada, as pessoas tendem a reformular suas identidades, englobando as transformações aos significados individuais e coletivos compartilhados. Por outro lado, quando as transformações não são integradas, podem desembocar em conflitos. Na comunidade estudada, as alterações nos ambientes físicos e simbólicos e as constantes ameaças de desapropriação começaram a transformar as relações comunitárias, desembocando em conflitos externos (com as/os agentes das transformações) e internos (entre as/os próprias/os moradoras/es). As/Os moradoras/es apontam que, inicialmente, as/os administradoras/ es começaram a descaracterizar a Vila como uma forma de aviso para deixarem o lugar:

Eles faziam ameaças, mostravam uns papéis, umas coisas, mas ninguém acreditava. Aí ia passando o tempo. ... Aí o negócio acalmou. Só que do jeito que veio agora foi a pior fase. Quando a Dejanira começou, foi que o negócio piorou. Que fez um contrato debaixo dos panos, de gaveta. Ela mandou derrubar a caixa d'água, ela alugou isso aqui [área frente da igreja] pra estacionamento da Uniodonto. Ela era administradora. Ela levou o altar, levou até São Vicente, que era pra acabar com a capela. Para descaracterizar (Entrevista de Capitã).

No auge do conflito, em outubro de 2016, três casas foram demolidas e outras cinco foram destelhadas. As ações de demolição não continuaram por interferência do Poder Público que, pressionado pela os advogados da comunidade e apoiadoras/es sociais, suspenderam as ações de demolição autorizadas na reintegração de posse. Nesse momento de destruição dos espaços físicos, as/os moradoras/es passaram a ver a comunidade de modo diferente, como aponta Cláudia: "Só o que eu acho diferente é que as casas foram destruídas, aí a Vila ficou feia, desorganizada" (Entrevista de Cláudia). Como as casas têm paredes conjugadas, algumas moradoras relataram que, com a demolição e/ou avarias feitas nas casas ao lado, elas passaram a achar a sua situação de moradia perigosa: "Perigoso e frágil. Mudou a insegurança... eu ainda mais, estou solta [casa]. Quando vou dormir de noite, coloco uma toalha nas persianas da porta para ninguém ver" (Entrevista de Marília).

Outra moradora relata que tem "Medo, me sinto triste em ver algumas casas destruídas pelas pessoas que querem sair por micharia” (Entrevista de Luciana). Tais ações iniciais, como a desfiguração dos espaços coletivos (destruição da caixa d'água, confisco do altar, aterramento de um cacimbão, etc.), as avarias às casas (demolições) e a percepção de que outras/os moradoras/es estão sendo individualistas ao ponto de "sair por micharia", interferem nos referenciais simbólicos da comunidade, de modo que as/os moradoras/es sintam que laços afetivos foram quebrados entre elas/eles, bem como sintam sentimentos de tristeza e aversão aos espaços "feios".

Dentre as consequências da perda dos referentes simbólicos das relações das pessoas com seus espaços e de suas relações sociais, podem ser citados a marginalização, o individualismo, a falta de solidariedade, o mal-estar pessoal e social (Pol \& Valera, 1999). É possível observar a ocorrências de tais situações na Vila, uma vez que houve ruptura de relações comunitárias, tentativas de roubos e invasões às casas das/os moradores e os "adoecimentos emocionais" mencionados pelas/moradores.

Com as alterações e as ameaças, as/os moradores apontaram elementos afetivos e sociais relacionados à insegurança em deixar a casa sozinha, o medo da efetivação da demolição da comunidade, receio de não saber para onde ir, a desunião entre as/os moradoras/es e as situações de vergonha e constrangimento por se estarem nessa situação. 
Essas percepções podem ser configuradas como (a) singulares, que dizem respeito ao modo como as ameaças afetam psicológica e afetivamente cada morador/a; e (b) coletivas que, atreladas às singulares, demarcam como ocorreram as mudanças na dinâmica comunitária.

Nas percepções singulares, as ameaças têm causado mudanças no "emocional" e no "psicológico", como diz Gordinha em sua entrevista: "Mexeu muito com a minha tranquilidade, meu emocional. Fiquei muito apreensiva quando toda essa situação começou. Pensei comigo mesma "meu Deus, onde eu vou morar?" (Entrevista de Gordinha). Nas falas das moradoras aparecem também referências a sentimentos e emoções de insegurança, preocupação, angústia, constrangimento, que apontam para como elas são, individualmente, afetadas. Outra moradora relata que as alterações "Afetou muito, a gente vai trabalhar e fica pensando na Vila, o psicológico da gente fica ruim. Quando passa caminhão ou um trator desde o dia da demolição, todos os moradores já ficam angustiados e correm para ver o que é" (Entrevista de Cida).

Relacionada às percepções particulares, observa-se também que a situação de desapropriação altera a dinâmica de toda a comunidade. Nesse caso, as percepções coletivas trazem elementos que se relaciona ao contexto comunitário, quando as angústias, as preocupações, os medos e as inseguranças particulares também se relacionam com a destruição da casa da/o vizinha/o, com a quebra dos vínculos, com desorganização e insegurança dos espaços da comunidade, etc. Nesse caso, percebe-se que o vínculo comunitário "Mudou um pouco porque a gente fica encabulada de chegar bem ali, perto das pessoas que a gente conhecia e agora não fala. Tem medo de dar um 'bom dia'. E isso é chato” (Entrevista de Zézé). Outra moradora afirma que "Antes eu falava com todo mundo, agora só com a metade. As amizades não são mais a mesma coisa que antes" (Entrevista de Aline).

A instabilidade quanto à permanência e as relações comunitárias têm ocasionado sentimentos de constrangimento, preocupação e vergonha: "O que mudou foi que comecei a me sentir constrangida, porque quando chega uma pessoa dizendo que você vai sair, com ameaças de que não vai levar nada, de uma hora pra outra, sem direito, me sinto muito ameaçada" (Entrevista de Maria). Tais situações podem demarcar o sofrimento ético-político vivido pelas/os moradoras/es. Esse sofrimento é caracterizado como a dor mediada pelas injustiças e desigualdades sociais (Sawaia, 2009), que "retrata a vivência cotidiana das questões sociais dominantes em cada época histórica, especialmente a dor que surge da situação social de ser tratado como inferior, subalterno, sem valor, apêndice inútil da sociedade" (Sawaia, 2011 , p. 104). Ao considerar as dimensões micro e macrossociais, o sofrimento ético-político não psicologiza ou individualiza o sofrimento, mas o posiciona na sociedade. Outras falas revelam essas vivências, a partir da insegurança quanto ao próprio destino: "Mudou porque a gente anda preocupado. Uns dizem que tá vendida e outros não” (Entrevista de Véi).

Embora o contexto de ameaças de desapropriação gere impactos negativos para a vida das/os moradoras/es, dentre eles a ruptura dos vínculos comunitários, impactos na dinâmica psicológica (identidade, por exemplo), etc., observou-se, também, implicações positivas que podem resultar no desenvolvimento de ações de resistência e enfrentamento das situações de sofrimento. Neste sentido, as/os moradoras/es relatam situações que repercutem no fortalecimento dos vínculos comunitários (dentre os que resistem à desapropriação), na transformação da comunidade a partir do resgate dos espaços "inativados", na reconstrução histórica da vida coletiva dos/as moradoras/es, no processo de conscientização a respeito dos problemas particulares, da comunidade e de toda a cidade, vendo que, muitas vezes, o sofrimento que vivenciam tem raízes mais profundas e dialogam com as raízes de outros sofrimentos sociais (Góis, 2005; Sawaia, 2011). 
Parte das/os moradoras/es organizou o movimento Resistência Vila Vicentina. Esse grupo tem realizado atividades comunitárias (Góis, 2005) a fím de mobilizar os demais moradoras/es e atrair apoiadoras/es para a causa, tais como universitárias/os, movimentos sociais e moradoras/es de outros bairros (Gondin \& Rocha, 2019). Ademais, com a mobilização e visibilidade do movimento, foi possível acionar serviços públicos de proteção, como o Escritório de Direitos Humanos e Assessoria Jurídica Popular Frei Tito de Alencar, órgão da Assembleia Legislativa do Estado do Ceará. Com esse suporte, "a gente sentiu menos preocupação" (Entrevista de Margarida).

Salienta-se, ainda, que essa resistência, por meio da participação, tem vários ganhos, que não se restringem às questões jurídicas e estruturais da comunidade. Como apontam Elvas e Moniz (2010), quando as/os moradoras/es participam ativamente da vida coletiva da comunidade, envolvem-se em questões políticas e mobilizações comunitárias, há uma diminuição nos níveis de baixos de satisfação de vida, tais como depressão, rejeição, solidão, agressividade, uso de drogas, etc.; o que repercute, ainda, em um aumento da satisfação e qualidade de vida.

\section{Afetos e implicações psicossociais}

As pessoas podem ser afetadas de muitas formas possíveis no contato uns com os outros, assim como as coisas que no mundo existem, por suas relações com os afetos humanos, também podem afetar no encontro com as pessoas (Espinosa, 2010). Como abordou-se anteriormente, as relações afetivas guiam as ações, podendo levar as pessoas à atividade como também à passividade (Espinosa, 2010; Sawaia, 2009). Nas entrevistas realizadas, duas perguntas feitas às/aos moradoras/es buscavam apreender os afetos da vivência na comunidade. Para apreender os afetos potencializadores, perguntou-se sobre o que alegrava na Vila, compreendendo a alegria como "uma paixão pela qual a mente passa a uma perfeição maior” (Espinosa, 2010, p. 177); já para apreender os afetos despotencializadores, foi perguntado sobre o que entristecia na Vila, tendo "uma paixão pela qual a mente passa a uma perfeição menor" (Espinosa, 2010, p. 177).

Desse modo, compreende-se a alegria como tudo aquilo que aumenta a potência de ação, que mobiliza a agir de modo mais autônomo; e a tristeza como aquilo que faz padecer, diminuindo a potência de ação, levando à passividade (Sawaia, 2009). Ressalta-se que os afetos não são concebidos de modo moralizantes, dados como "bons" ou "maus" em si mesmos, mas a partir da forma como o indivíduo o percebe como útil a si, pois "uma única e mesma coisa pode ser boa e má ao mesmo tempo e ainda indiferente”, sendo boa quando se torna em algo útil e má quando impede o acesso ao bom (Espinosa, 2010, p. 267). Na Figura 01, tem-se a síntese dos afetos relatados pelas/os moradoras/es. 
Figura 01 - Síntese das emoções e sentimentos no atual contexto

Afetos Potencializadores

Segurança e tranquilidade: $4^{*}$

Esperança e fé: 5

Bem: 4

Força (fortalecimento): 3

Felicidade: 2

\section{Afetos Despotencializadores}

Insegurança e ameaça: 5

Medo: 1

Angústia: 1

Desconforto: 1

Preocupação: 1

Ansiedade: 1

Aflição: 1

Fonte: Elaborado pelos autores.

* Os números estão relacionados à quantidade de vezes que esses elementos foram citados, não a quantidade de pessoas que os apontaram.

$\mathrm{Na}$ literatura espinosana, a fé e a esperança aparecem como afetos passivos, que contribuem para a permanência da servidão (Sawaia, 2009). De modo análogo, Martin-Baró (2017) aponta que, muitas vezes, as pessoas pobres vivenciam esses sentimentos como características de um sentimento fatalista. No entanto, considerando a utilidade dos sentimentos em decorrência dos contextos (Espinosa, 2010) nos quais se configuram, esses afetos aparecem como potencializadores por terem sido apontados pelas/os moradoras/es como fatores que os mobilizam para a luta.

Ao mapear elementos (causas/situações) que alegram os moradores, foram identificados a vizinhança/ união entre as/os moradoras/es, própria moradia (permanência), diversão entre as/os moradoras/es, a segurança e a família. Já quanto aos elementos que entristecem, observa-se a desunião entre as/os moradoras/es, o ato de desapropriação, demolição das casas, insegurança e morte. A Figura 02 apresenta a síntese desses elementos. 
Figura 02 - Síntese dos elementos alegres e tristes

Elementos Potencializadores

(O que alegra)

\section{Elementos Despotencializadores (O que entristece)}

Vizinhança/

União entre os moradores: $9^{*}$

Própria moradia (permanência): 5

Diversão entre os moradores: 3

Segurança: 2

Família: 2
Desunião entre os moradores: 7

Venda da Vila (Desapropriação): 6

Demolição das casas: 5

Insegurança: 1

Morte: 1

Fonte: Elaborado pelos autores.

*Os números estão relacionados à quantidade de vezes que esses elementos foram citados, não a quantidade de pessoas que os apontaram.

Os elementos que mais se destacam como aqueles que deixam as/os moradoras/es alegres estão relacionados à (a) união entre as/os moradoras/es e à (b) própria casa/contexto de moradia. Quanto ao primeiro elemento, a integração entre eles tem implicações potencializadoras diretamente relacionadas ao movimento de resistência, expressando-se pelos sentimentos de apoio mútuo e construção de atividades de mobilização e enfrentamento. A esse respeito, Gordinha traz como alegria "morar aqui e continuar a vida aqui, as pessoas que conhecemos" (Entrevista de Gordinha). Além dessa integração, destacam-se as interações rotineiras, como aponta Véi: "Me alegra as brincadeiras que a gente faz, os jogos de baralho" (Entrevista de Véi).

No que diz respeito ao segundo elemento de alegria, a própria moradia, observa-se a presença da percepção de estabilidade e segurança, caracterizando-se como um espaço de proteção, aconchego e construção de história compartilhada. Como se pode observar na fala de Capitã: "O que me alegra é a segurança, a proteção que sinto quando saio e volto para a minha casa” (Entrevista de Capitã). Já Margarida reforça a construção de sua história na comunidade: "Há tanta coisa que me alegra, meus filhos, tudo alegra, porque tive meus filhos tudo aqui” (Entrevista de Margarida).

Pode-se compreender esses afetos e elementos potencializadores como característicos do sentido comunidade ou sentimento de pertença. Este pode ser compreendido como o modo como moradores se sentem pertencentes ao lugar, fazendo parte de um grupo de pessoas, onde todos têm importância uns para os outros, compartilham crenças, costumes e hábitos e, em consequência dessa convivência, sentem-se protegidos e consideram que suas necessidades são atendidas (Mcmillan \& Chavis, 1986). Ao desenvolver ações que potencializem os elementos alegres, pode-se fortalecer o sentimento de comunidade, ocasionando o aumento de satisfação e qualidade de vida dos indivíduos, funcionando como recursos para a proteção da saúde biopsicossocial (Elvas \& Moniz, 2010).

Em relação aos elementos que mais entristecem, há destaque para a (a) desunião entre as/os morador/ases e a (b) possibilidade de que a comunidade seja vendida/demolida, gerando sentimentos de insegurança, preocupações, desconforto, angústia, medo, etc. 
Quanto ao primeiro elemento de entristecimento, essa desunião está relacionada à divisão da comunidade entre aquelas/es que resistem à desapropriação e aquelas/es que buscam negociar suas casas. A esse respeito, a moradora Cláudia diz: "Me deixa triste é que meus dois vizinhos que são paredes junto da minha são do outro lado. Uma que era minha amiga fica soltando piada, aí me deixa triste" (Entrevista de Cláudia). Aline também vivencia tristeza por conta das "ameaças, desavenças, essas intrigas por parte deles. Antes todos se falavam, agora não, ficam soltando piadas" (Entrevista de Aline).

A possibilidade de ver a comunidade vendida/demolida aparece como outro elemento que entristece as/os moradoras/es, principalmente porque, estruturalmente, pode representar a perda de um lugar de proteção e segurança, pelas oportunidades que as moradoras têm de acesso à cidade, pelas incertezas quanto a um novo lugar para morar, etc. A esse respeito Capitã relata que "Como já perdi pai, mãe, todos os meus irmãos, já sou idosa e solteira, sem filhos, assalariada, como eu mesma me manteria pagando aluguel em um lugar da igual qualidade da Vila Vicentina?" (Entrevista de Capitã). O morador J. também pensa semelhante a Capitã, afirmando ter "Muita preocupação com a moradia, pois sei que não encontrarei lugar melhor em Fortaleza" (Entrevista de J.). Quanto às negociações, Gordinha relata que a "entristece essas pessoas pedindo para morar aqui e agora querem sair, negociar, ganhar dinheiro" (Entrevista de Gordinha).

É importante ressaltar que a localização da comunidade apresenta fortes implicações sociais e políticas, explicitando marcas ideológicas. No caso da Vila, situada em uma área de grande valorização imobiliária, a opressão se dá também pelo valor econômico e simbólico do espaço físico. Espaço que, pela representação da desigualdade social, não deve pertencer aos pobres. A possibilidade de reassentamento da comunidade em outro espaço denota, assim, um processo de inclusão-exclusão, uma vez que as comunidades removidas em Fortaleza são realocadas em bairros periféricos ou região metropolitana, já em situações precárias.

A demolição da Vila está fortemente vinculada à deterioração de parte da identidade, pessoal e coletiva das/os moradoras/es, juntamente com suas memórias e histórias. Cida afirma que lhe entristece "A derrubada das casas também deixou feio, atrai coisa ruim para cá” (Entrevista de Cida). Margarida também fica triste com “... a derrubada das casas, a desunião do pessoal que quer sair. Era pra tudo estar unido” (Entrevista de Margarida). Filho aponta que sua vida mudou totalmente com as ameaças de desapropriação, destacando que "A minha vida sempre residi aqui na Vila, não imagino morar em outro local a não ser a Vila" (Entrevista de Filho), denotando que "estar emocionalmente apegado a um lugar faz com que seja mais difícil apegar-se a outro” (Giuliani, 2004, p. 95).

Outro ponto de grande destaque no entristecimento diz respeito aos conflitos internos na Vila. Guareschi (2007) afirma que, para compreender as relações comunitárias, devemos enxergar a "relação" como uma coisa que não pode existir sem outra coisa que possa completá-la. Geralmente, as pessoas tendem a acreditar que relação é somente aquilo que une uma coisa à outra positivamente. No entanto, conforme o autor, as relações também podem ser conflituosas, de exclusão e rejeição. No atual contexto da Vila, as relações entre as/os moradoras/es têm sido marcadas tanto pela integração quanto pela desunião. A Figura 03, abaixo, apresenta relatos sobre a configuração dessas relações em contexto de ameaça de desapropriação: 
Figura 03 - Configurações das relações comunitárias

\section{União}

\section{Desunião}

Me entristece a divisão de alguns querendo sair e outros querendo ficar, gerando conflito.

A derrubada das casas também

Me alegra que somos unidos, todos se conhecemos. (Entrevista de Cida)

Me alegra quando tem brincadeira, tem momentos unidos, ai é alegria. Todo mundo junto (Entrevista de Cláudia)

Me alegra a união dos moradores que querem ficar na Vila (Entrevista de Filho)

O que me alegra é morar aqui e continuar a vida aqui, as pessoas que conhecemos

(Entrevista de Gordinha)

Alegra as pessoas, as festinhas

(Entrevista de Maria)

Me alegra o modo e a convivência de alguns moradores (Entrevista de Zil)

O que me alegra são os amigos que tenho uma boa vizinhança (Entrevista de J.)

Me alegra as brincadeiras que a gente faz, os jogos de baralho. (Entrevista de Véi)

- Me alegra a minha família, os vizinhos que tenho são muito bons, graças a Deus. Só faço é rezar por tudinho (Entrevista de Zezé) deixou feio, atrai coisa ruim para cá

(Entrevista de Cida)

Me deixa triste é que meus dois vizinhos que são paredes junto da minha são do outro lado. Uma que era minha amiga fica soltando piada, aí me deixa triste.

(Entrevista de Cláudia)

Me entristece essas pessoas pedindo para morar aqui e agora querem sair, negociar, ganhar dinheiro. (Entrevista de Gordinha)

Me deixa triste a derrubada das casas, a desunião do pessoal que quer sair. Era pra tudo estar unido. (Entrevista de Margarida)

Me entristece essas confusões, desuniões. Podia ser muito melhor se fosse todo mundo unido, na paz. (Entrevista de Eunice)

Me deixa triste essas ameaças, desavenças, essas intrigas por parte deles. Antes todos se falavam, agora não, ficam soltando piadas.

(Entrevista de Aline)

Me entristece certas besteiras de gente que gosta de abrir a boca e dizer besteira. Mas eu não ligo (Entrevista de Zezé)

Fonte: Elaborado pelos autores.

No que diz respeito à união, o próprio fato de pertencer à comunidade fortalece os vínculos entre as/os moradoras/es, uma vez que a convivência diária ao longo dos anos (com momentos de jogos, festividades, apoio, etc.) reforça as características relacionadas ao sentido de comunidade (Mcmillan \& Chavis, 1986). No caso da Vila, a união possibilitou a organização do movimento Resistência Vila Vicentina, por meio do qual realizam atividades a fim de obter visibilidade para as suas causas e criar estratégias de enfrentamento da situação. Com as atividades desenvolvidas, observa-se o alcance de mecanismos legais de defesa do direito à cidade e a participação em outros movimentos sociais que lutam pela permanência na cidade (Gondin \& Rocha, 2019). Destaca-se, ainda, essa integração e o desenvolvimento das atividades sociais e políticas podem contribuir para a superação do sofrimento ético-político, a partir do alcance da felicidade pública, que ultrapassa as 
práticas individualistas e é "experienciada pelos que sentem a vitória como conquista da cidadania e da emancipação de si e do outro, e não apenas de bens materiais circunscritos" (Sawaia, 2011, p. 107). A felicidade pública se configura como um ato político, em que a sua busca revela também um processo de conscientização, resultado de uma decisão autônoma de não obedecer aos comandos exteriormente determinados (Sawaia, 2009).

Quanto à desunião, observa-se que a fragilidade e ruptura dos laços sociais vêm cada vez mais gerando conflitos internos, como aponta Cida: "Me entristece a divisão de alguns querendo sair e outros querendo ficar, gerando conflito" (Entrevista de Cida). Gondin e Rocha (2019) afirma que o dilema principal entre as/os moradoras/es que querem negociar suas casas se dá sob pressão que as/os tornam polarizadas/os entre o sair da comunidade "com alguma coisa" ou resistir contra "pessoas poderosas" e sair "sem nada", o que acaba por acirrar ainda mais os conflitos internos na comunidade.

No entanto, acredita-se que, assim como as/os moradoras/es que pretendem ficar, é possível que as/os que "querem sair" tenham medos e inseguranças quanto à permanência no lugar de moradia e aceitem a negociação em decorrência da possibilidade de ficar desamparada/o. Como as imobiliárias, estrategicamente, colocam como condicionalidade para a efetivação negociação a saída de todas/os as/os moradoras/es, há o aumento das tensões e conflitos, que resultam em desrespeito e rompimento dos vínculos comunitários, enfraquecendo a comunidade. Tal clima de insegurança perante as negociações pode ser visto como uma estratégia de desmobilização social, afetando diretamente os movimentos de resistência dos atingidos (Ascerald, Mello, \& Bezerra, 2009).

Por fim, deve-se entender, como aponta Góis (2008, p. 85), que toda comunidade tem “... um processo sociopsicológico próprio, cheio de contradições e antagonismos e interesses comuns, que servem de construção e orientação das ações dos moradores em relação ao próprio lugar e à sua inserção no conjunto da sociedade”. Desse modo, acredita-se que a compreensão dessas relações auxilia no desenvolvimento de processos de intervenções/ facilitações que podem tanto fortalecer a resistência e enfrentamento das ameaças como auxiliar na diminuição dos conflitos.

\section{Considerações finais}

A análise afetiva permite compreender que, em contextos de remoção de comunidades, as pessoas não perdem só as casas, mas têm uma teia social, simbólica e psicológica impactada. Como expressão da desigualdade e segregação socioespasocial, a desapropriação de comunidades pobres pode, ainda, contribuir para o aumento do sofrimento ético-político, ao trazer às pessoas vivências de inclusão-exclusão social, marcadas pela vergonha, humilhação, constrangimento e insegurança quanto à permanência no próprio abrigo.

No entanto, destaca-se que a compreensão desse fenômeno apontou que não há somente afetos despotencializadores, mas também implicações que potencializam a força de ação, repercutindo no fortalecimento dos vínculos comunitários e, consequentemente, na realização de atividades comunitárias direcionadas para a superação do conflito. Com efeito, a partir da afetividade, identificou-se elementos que potencializam as ações das/os moradoras/es em prol da resistência à desvinculação; assim como também encontrou-se os indicativos despotencializadores, os quais, olhados ético politicamente, podem ser transformados com o objetivo de diminuir impactos sofridos. 
Por fim, pontua-se que o estudo foi realizado somente com moradoras/es que resistem à desapropriação, sendo necessário também apreender as percepções sociais e afetivas do outro lado que "deseja sair da comunidade". Acredita-se, no entanto, que parte dessa decisão de "partir" decorra dos medos de estar "lutando contra pessoas poderosas" e acabarem por "sair sem nada". Nesse caso, pode haver um domínio dos afetos despotencializadores, repercutindo em uma postura fatalista, característica de uma dor marcada pelas injustiças sociais.

\section{Nota}

1 Albuquerque, Maria Onira de. (1970) Cordel A História da Vila Cinzenta. Fortaleza. (Não publicado).

\section{Referências}

Acselrad, H., Mello, C. C. A., \& Bezerra, G. N. (2009). O que é justiça ambiental. Garamond. Bardin, Laurence (1977). Análise de Conteúdo. Edições 70.

Bomfim, Z. A. C. (2010). Cidade e Afetividade: Estima e Construção de Mapas Afetivos de Barcelona e São Paulo. Edições UFC.

Bomfim, Z. A. C., Delabrida, Z., \& Ferreira, K. (2018). Emoções e afetividade ambiental. In S. Cavalcante \& G. Elali (Orgs.), Psicologia Ambiental: conceitos para a leitura da relação pessoa-ambiente (pp.60-74). Vozes.

Cavalcante, S. \& Elali, T. F. (2011). Apropriação. In Temas básicos em Psicologia Ambiental (pp. 63-69). Editora Vozes.

Duarte, R. et al. (2017). Contribuição técnica ao tombamento municipal da Vila Vicentina da Estância, em Fortaleza-CE. UFC.

Elvas, S. \& Moniz, M. J. V. (2010). Sentimento de comunidade, qualidade e satisfação de vida. Análise Psicológica, 28(3), 45 1-464. Recuperado de http://www.scielo.mec.pt/scielo.php?script =sci arttext\&pid=S0870-82312010000300006\&lng=pt\&tlng=pt

Espinosa, B. (2010). Ética. Autêntica.

Gaskell, G. (2002). Entrevistas individuais e grupais. In M. Bauer \& G. Gaskell (Eds.), Pesquisa qualitativa com texto, imagem e som: um manual prático (pp. 64-89), Vozes.

Giuliani, M. V. (2004). O lugar do apego nas relações pessoas-ambiente. In E. T. O. Tassara, T. O. Eda, E. P. Rabinovich, \& M. C. Guedes (Eds.), Psicologia e Ambiente (pp. 89-1-6). Educ.

Góis, C. W. L. (2005). Psicologia Comunitária: atividade e consciência. Publicações Instituto Paulo Freire de Estudos Psicossociais.

Góis, C. W. L. (2008). Saúde Comunitária: pensar e fazer. Hucitec.

Gondin, L. \& Rocha, A. (2019). Repertórios de confronto em movimentos sociais urbanos: os casos da Resistência Vila Vicentina e do Quem Dera Ser um Peixe, em Fortaleza-CE, Revista de Ciências Sociais (UFC), 50, 365-407. 
Guareschi, P. (2007). Relações comunitárias: relações de dominação. In R. H. F Campos (Org.), Psicologia Social Comunitária: da solidariedade à autonomia (pp. 81-89). Vozes.

Instituto de Planejamento de Fortaleza - Iplanfor. (2020). Diagnóstico Socioeconômico, Histórico-cultural, Arquitetônico e Fundiário (Zeis Dionísio Torres). Autor.

Lane, S. (2006). A mediação emocional na constituição do psiquismo humano. In S. T. M Lane \& B. B. Sawaia (Orgs.), Novas veredas da Psicologia Social (pp. 55-66). Brasiliense.

Martín-Baró, I. (2017). Crítica e libertação na psicologia. Vozes.

McMillan, D.W. \& Chavis, D.M. (1986). Sense of community: A definition and theory. American Journal of Community Psychology, 14(1), 6-23.

Montero, M. (2004). Introducción a la psicología comunitaria. Paídos.

Pacheco, F. P., Martins, C. M. S. S., \& Bomfim, Z. Á. C. (2020). Contribuições da psicologia para a análise de desapropriações de comunidades dos espaços urbano e rural cearenses. Revista De Psicologia, 11(2), 132-140. https://doi.org/10.36517/10.36517/revpsiufc.11.2.2020.14 Pol, E. (1996). La apropiación del espacio. In L. Iñigues \& E. Pol (Orgs.), Cognición, representación y apropiación del espacio (pp. 45-62). Monografies Sócio/ambientais.

Pol, E. \& Valera, S. (1999). Symbolisme de l'espace public et identitée sociale. Villes en Paralèlle, 28(29), 13-33.

Sawaia, B. B. (2009). Psicologia e desigualdade social: uma reflexão sobre liberdade e tranformação social. Psicologia E Sociedade, 21(3), 364-372. https://doi.org/10.1590/So102$\underline{71822009000300010}$

Sawaia, B. B. (2011). O sofrimento ético-político como categoria de análise da dialética exclusão/inclusão. In As artimanhas da exclusão: uma análise ético-psicossocial da desigualdade (pp. 97-119). Vozes.

\section{FÁBIO PINHEIRO PACHECO}

https://orcid.org/0000-0003-4139-1506

Mestre e doutorando em Psicologia pelo Programa de Pós-graduação em Psicologia da Universidade Federal do Ceará, Fortaleza, Ceará, Brasil.

E-mail: pfabiopinheiro@gmail.com

\section{ZULMIRA ÁUREA CRUZ BOMFIM \\ https://orcid.org/0000-0003-1773-0061}

Doutorado em Psicologia Social pela Pontifícia Universidade Católica de São Paulo, Professora do Departamento de Psicologia da Universidade Federal do Ceará, Fortaleza, Ceará.

E-mail: zuaurea@gmail.com 


\begin{tabular}{|c|c|}
\hline Histórico & $\begin{array}{l}\text { Submissão: 27/02/2021 } \\
\text { Revisão: 29/09/2021 } \\
\text { Aceite: } 28 / 10 / 2021\end{array}$ \\
\hline $\begin{array}{l}\text { Contribuição } \\
\text { dos autores }\end{array}$ & $\begin{array}{l}\text { Concepção: F.P.P. } \\
\text { Coleta de dados: F.P.P. } \\
\text { Análise de dados: F.P.P. } \\
\text { Elaboração do manuscrito: F.P.P.; Z.A.C.B. } \\
\text { Revisões críticas de conteúdo intelectual importante: } \\
\text { F.P.P.; Z.A.C.B. } \\
\text { Aprovação final do manuscrito: F.P.P.; Z.A.C.B. }\end{array}$ \\
\hline Financiamento & $\begin{array}{l}\text { A pesquisa foi financiada pela Fundação Cearense de Apoio ao } \\
\text { Desenvolvimento Científico e Tecnológico (FUNCAP), por meio de } \\
\text { concessão de bolsa de pesquisa ao Programa de Pós-Graduação em } \\
\text { Psicologia da Universidade Federal do Ceará (PPGP/UFC). }\end{array}$ \\
\hline $\begin{array}{l}\text { Aprovação, ética } \\
\text { e consentimento }\end{array}$ & $\begin{array}{l}\text { A pesquisa obteve aprovação pelo Comitê de Ética em Pesquisa } \\
\text { da Universidade Federal do Ceará (CEP/UFC), com CAAE: } \\
\text { 80786817.5.0000.5054, e número do parecer: } 2.456 .364 .\end{array}$ \\
\hline
\end{tabular}

